\title{
Ingenious Practices in Neurodegenerative Diseases-Cognitive Medicine and Neuromodulation
}

\author{
Jes Paul* \\ Department of Molecular and Cellular Physiology, USA \\ Received: October 30, 2018; Published: November 28, 2018 \\ *Corresponding author: Jes Paul, Department of Molecular and Cellular Physiology, Albany Medical College, USA
}

\section{Introduction}

One of the major challenges of today's society is to call for more knowledge about how to maintain all aspects of cognitive health during the life course. Neuromodulation is an umbrella term which refers to the approach of using physical intervention to interfere with the nervous system and modify its functioning with the purpose of bringing benefits. It aims to restore the function of disrupted neural circuits and to relieve neurological and psychiatric symptoms. Their use in medical treatment, they provide unique opportunities to study brain networks underlying human cognition and emotion.

\section{Cognitive Medicine}

The main focus of Uncover cellular and molecular mechanisms underlying decline of cognition functions. Integrate research on behavioural, cellular, molecular mechanisms associated with cognitive dysfunction in diverse disorders-idea of cognitive medicine. Disability induced by cognitive dysfunction-major issue in patients suffering from PD or Alzheimer's. Cognitive failure causes disability which cause major failure in work force. Cognitive impairments are unambiguously linked to disability.

Knowledge from cognitive medicine can clarify the role of current memory clinics to form health care units. The key cognition functions are visiospatial function, attention, learning and memory, language and social cognition. Cognitive medicine is an umbrella term which involves how to prevent, diagnose and cope up with cognitive decline. All process used in interactions with other humans and the environment are cognitive (from visual perception to social cognition) that is it influences emotional reactions and decision making. According to WHO, disability is an umbrella covering term for impairments, activity limitations and restriction in participation. There is high prevalence of advanced cognitive impairment in elderly individuals with increasing age-related brain diseases [1].

In a wide spectrum of medical conditions -cognitive impairment is an Essential symptomatology. Cognitive assessment can be used to distinguish Alzheimer's disease from other emending disorders such as sub cortical small vessel disease (cognitive pattern of early dysfunction of mental speed and executive capacity,) and to evaluate to what extend is coexistence of the conditions [2,3]. 47 million people have cognitive impairment worldwide (WHO) and estimation is that in 2030 and 2050 will be 75 and 135 million respectively. Using cognitive profiling, the affected and vascular pathways can be detected in Alzheimer's patients [4,5]. Continuous development of tools, restorative and compensatory measures are of great importance.

\section{Effect of Cognitive Implications on Life}

The focus area of cognitive medicine is cognitive dysfunction during work life. Larger work life and need of skill development demands increased cognition performance. Social as well as meta cognition plays an important role here. Social cognition points the social interactions that understands either person's wishes and needs whereas Meta cognition is the ability to reflex upon one's own cognitive processes. By 10 years of age a child would've already undergone substantial development in cognitive function. As the age increases the cognition functions are also affected. Age sensitive cognitive functions are working memory, attentional functions, episodic long-term memory, and several executive functions whereas the age independent cognitive functions are memory of facts and social cognition $[6,7]$.

Activity limitation corresponds to difficulty in executing a task function and Participation restriction corresponds to restriction to involve in life situations. cognitive medicine also investigates whether cognitive disorders late in life an associated with or even casually linked to lifestyle related diseases earlier in life such as hypertension, diabetes and obesity. In aging population there is increased stress related disorders, increased sedentary lifestyle, increased cognitive impairment. Lack of exercise and obesity also correlate with decreased cognitive performance even in small ages. Considering research in cognitive medicine worldwide address how to design successful early prevention 
and interventions in children and adults in order to develop and maintain an active lifestyle thereby increasing resilience against cognitive dysfunctions throughout the life course.

\section{Neuromodulation}

Neuromodulation is the cortical and sub cortical approaches to manage neuropsychiatric disorders. The Burden of neurological disease has significant economic and social impact. Basic and applied medical research merging with engineering design method catalyse next generation neuromodulate therapeutics. Neuromodulation 2.0: can serve as a bridge from today's tonic pulse generators to tomorrow's adaptive neurological "co-processors."

\section{New Approaches}

Newer devices are now which will likely facilitate the ability to sample two channels per lead; the use of additional channels could be beneficial to both increase sampling and to pair stimulation in closed-loop devices. Variable Frequency Stimulation (VFS) was well tolerated and was shown to potentially reduce FOG episodes and improve TUG measures. In PD patients, using VFS both FOG and appendicular symptoms decreases whereas IFS worsen appendicular symptoms. For Essential Tremor and Dystonia, Biphasic DBS is used. sqBiP DBSmore and increased tolerability in patients with PD, dystonia and ET. It aids in adjusting pulse frequency and shape of pulse. In dystonia patients there is improvement in gait variable. In et-improved tremor scale and accelerometer parameters are seen [8]. Distributed Network Control with High Density Neuromodulation Technology is a new approach to Intractable Epilepsy. Older methods, Anterior thalamic DBS Salanova et al. (2015) and responsive neuromodulation Bergey et al. (2015) for treatment epilepsy has been reported to show an approximately $65 \%$ reduction in seizures at long term follow-up. But in vitro multi-electrode array in cell culture revealed that asynchronous multi-site stimulation eliminated synchronous epileptogenic activity. Multi-microelectrodes were more effective than macro electrodes in terminating seizures in a rodent model using asynchronous theta stimulation.

Closed Loop DBS is a new advancement in PD [Parkinson's disease] [9]. Symptom improvement, with substantial power savings and/or reduction in side-effects attributable to stimulation. In PD, by closed loop -more précised and customized neuromodulation based on state, symptom and level of medication. Tremor and FOG (Freezing of Gait) in pd also can be improved as it varies in amplitude or pressure over time and differ between patients. This Approach appears safe and applicable [10]. While in the older method of open loop cannot respond to patient state and dominant symptoms.

An innovative approach, VNS (vagus nerve stimulation) improves working memory performance and enhances visual attention providing novel support for its benefits on cognition in treatment of patients with epilepsy. VNS has immediate effects on affective and cognitive functions as indicated by behavioural and brain responses to emotional threat-related stimuli [11].

\section{Conclusion}

Since cognitive and emotional health is critical for life quality, optimal medical treatment should alleviate symptoms of the disease while minimizing adverse cognitive and emotional effects. Therefore, elucidating the effects of neuromodulation on human cognition and emotion are neuroscientifically valuable and clinically essential. This review highlights the effects of neuromodulation on human executive functions and to investigate the underlying cognitive and affective circuits. These studies bear clinical significance by providing potential behavioural and electrophysiological biomarkers for the cognitive and affective effects of neuromodulation treatment.

\section{References}

1. (2018) World Health Organization. Disabilities.

2. Wallin A, Nordlund A, Jonsson M, Blennow K, Zetterberg H, et al. (2016) Alzheimer's disease-subcortical vascular disease spectrum in a hospital-based setting: overview of results from the Gothenburg MCI and dementia studies. J Cereb Blood Flow Metab 36(1): 95-113.

3. Rosenberg GA, Wallin A, Wardlaw JM, Markus HS, Montaner J, et al. (2016) Consensus statement for diagnosis of subcortical small vessel disease. J Cereb Blood Flow Metab 36(1): 6-25.

4. Wallin A (1998) The overlap between Alzheimer's disease and vascular dementia: the role of white matter changes. Dement Geriatr Cogn Disord 9(Suppl 1): 30-35.

5. Blennow K, de Leon MJ, Zetterberg H (2006) Alzheimer's disease. Lancet 387-403.

6. Josefsson M, de Luna X, Pudas S, Nilsson LG, Nyberg L (2012) Genetic and lifestyle predictors of 15-year longitudinal change in episodic memory. J Am Geriatr Soc 60(12): 2308-2312.

7. Vos T, Barber RM, Bell B, Bertozzi Villa A, Biryukov S, et al. (2015) Glob$\mathrm{al}$, regional, and national incidence, prevalence, and years lived with disability for 301 acute and chronic diseases and injuries in 188 countries, 1990-2013: a systematic analysis for the global burden of disease study 2013. Lancet 386: 743-800.

8. Valdez P, Ramírez C, García A (2012) Circadian rhythms in cognitive performance: implications for neuropsychological assessment. Chrono Physiology and Therapy 2: 81-92.

9. Rosin B, Slovik M, Mitelman R, Rivlin Etzion M, Haber SN, et al. (2011) Closed-loop deep brain stimulation is superior in ameliorating parkinsonism. Neuron 72(2): 370-384.

10. Nutt JG, Bloem BR, Giladi N, Hallett M, Horak FB, et al. (2011) Freezing of gait: moving forward on a mysterious clinical phenomenon. Lancet Neurol 10(8): 734-744.

11. Vandewalle G, Schwartz S, Grandjean D, Wuillaume C, Balteau E, et al. (2010) Spectral quality of light modulates emotional brain responses in humans. Proceedings of the National Academy of Sciences of the United States of America 107(45): 19549-19554. 
(c) (i) This work is licensed under Creative Commons Attribution 4.0 Licens BY DOI: 10.19080/OAJS.2018.10.555778

\section{Your next submission with Juniper Publishers will reach you the below assets}

- Quality Editorial service

- Swift Peer Review

- Reprints availability

- E-prints Service

- Manuscript Podcast for convenient understanding

- Global attainment for your research

- Manuscript accessibility in different formats

( Pdf, E-pub, Full Text, Audio)

- Unceasing customer service

Track the below URL for one-step submission https://juniperpublishers.com/online-submission.php 